\section{BRAZILIAN JOURNAL \\ OF MEDICAL AND BIOLOGICAL RESEARCH}

www.bjournal.com.br
ISSN 1414-431X

Volume 45 (12) 1102-1340 December 2012

\section{BIOMIDICAL SCIENCES}

AND

CLINICAL INVESTIGATION

Braz J Med Biol Res, December 2012, Volume 45(12) 1172-1182

doi: 10.1590/S0100-879X2012007500166

Acute effects of resistance exercise and intermittent intense aerobic exercise on blood cell count and oxidative stress in trained middle-aged women

A.M. Cardoso, M.D. Bagatini, M.A. Roth, C.C. Martins, J.F.P. Rezer, F.F. Mello, L.F.D. Lopes,

V.M. Morsch and M.R.C. Schetinger

The Brazilian Journal of Medical and Biological Research is partially financed by

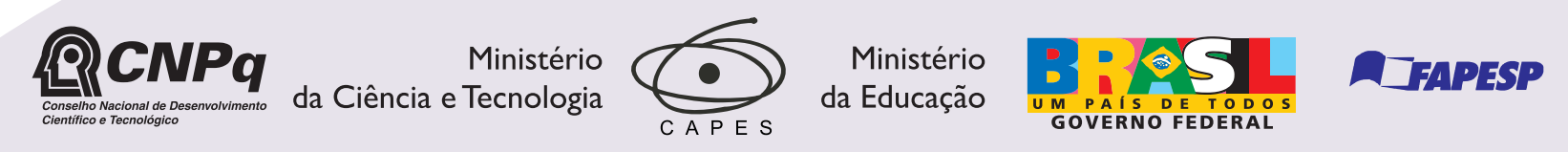

Institutional Sponsors

Scie/
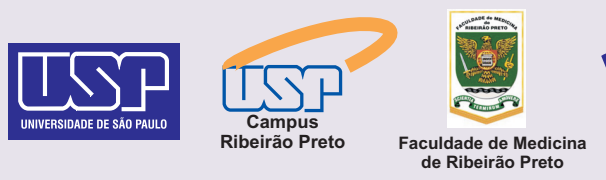

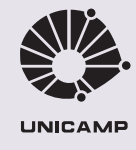

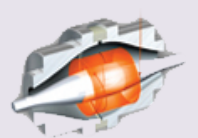

Ф SHIMADZU

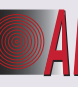

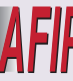
Fundo de Incentivo
à Pesquisa

plore High - Performance MS Orbitrap Technology analitica Thermo 


\title{
Acute effects of resistance exercise and intermittent intense aerobic exercise on blood cell count and oxidative stress in trained middle-aged women
}

\author{
A.M. Cardoso ${ }^{1}$, M.D. Bagatini ${ }^{4}$, M.A. Roth ${ }^{2}$, C.C. Martins ${ }^{1}$, J.F.P. Rezer ${ }^{1}$, \\ F.F. Mello ${ }^{2}$, L.F.D. Lopes ${ }^{3}$, V.M. Morsch ${ }^{1}$ and M.R.C. Schetinger ${ }^{1}$ \\ 1Departamento de Química, Centro de Ciências Naturais e Exatas, \\ Universidade Federal de Santa Maria, Santa Maria, RS, Brasil \\ 2Departamento de Desportos Individuais, Centro de Educação Física e Desportos, \\ Universidade Federal de Santa Maria, Santa Maria, RS, Brasil \\ ${ }^{3}$ Departamento de Administração, Centro de Ciências Sociais e Humanas, \\ Universidade Federal de Santa Maria, Santa Maria, RS, Brasil \\ ${ }^{4}$ Curso de Enfermagem, Campus Chapecó, Universidade Federal da Fronteira Sul, \\ Chapecó, SC, Brasil
}

\begin{abstract}
The aim of this study was to compare the effect of an intermittent intense aerobic exercise session and a resistance exercise session on blood cell counts and oxidative stress parameters in middle-aged women. Thirty-four women were selected and divided into three groups: RE group (performing 60 min of resistance exercises, $N=12$ ), spinning group (performing 60 min of spinning, $N=12$ ), and control group (not exercising regularly, $N=10$ ). In both exercise groups, lymphocytes and monocytes decreased after 1 -h recuperation (post-exercise) compared to immediately after exercise $(P<0.05)$. Immediately after exercise, in both exercised groups, a significant increase in TBARS (from $16.5 \pm 2$ to $25 \pm 2$ for the spinning group and from $18.6 \pm 1$ to $28.2 \pm$ $3 \mathrm{nmol} \mathrm{MDA} / \mathrm{mL}$ serum for the RE group) and protein carbonyl (from $1.0 \pm 0.3$ to $1.6 \pm 0.2$ for the spinning group and from 0.9 \pm 0.2 to $1.5 \pm 0.2 \mathrm{nmol} / \mathrm{mg}$ protein for the RE group) was observed $(P<0.05)$. A decrease in antioxidant activities (non-protein sulfhydryl, superoxide dismutase, catalase) was also demonstrated with a negative correlation between damage markers and antioxidant body defenses $(P<0.05)$. These results indicate that an acute bout of intermittent or anaerobic exercise induces immune suppression and increases the production of reactive oxygen species, causing oxidative stress in middle-aged and trained women. Furthermore, we demonstrated that trained women show improved antioxidant capacity and lower oxidative damage than sedentary ones, demonstrating the benefits of chronic regular physical activity.
\end{abstract}

Key words: Intermittent exercise; Anaerobic exercise; Oxidative stress; Immune suppression; Middle-aged women

\section{Introduction}

With the aging process, especially in women after menopause, there is a natural increase of reactive oxygen species (ROS) accompanied by a decrease of the immune response $(1,2)$. However, it is well accepted that regular physical training up-regulates the antioxidant enzymatic systems and stimulates the immune system, which may have implications for attenuating the usual increase in aging-related oxidative stress and immune suppression in this population $(1,2)$.
When physical activity induces muscle damage, the immune response becomes elevated, activating leukocytes and their differential cellular subtypes to release inflammatory signaling molecules. This culminates with the migration of inflammatory cells into the tissue $(1,3)$. High-intensity exercises are associated with a biphasic change of circulating leukocytes. In the immediate post-exercise period, an increase in the total number of leukocytes is observed, which mainly occurs at the expense of lymphocytes, neutrophils

Correspondence: M.R.C. Schetinger, Departamento de Química, Centro de Ciências Naturais e Exatas, Universidade Federal de Santa Maria, 97105-900 Santa Maria, RS, Brasil. Fax: +55-55-3220-8978. E-mail: mariachitolina@gmail.com or necaroth@gmail.com

Received November 19, 2011. Accepted August 20, 2012. Available online October 26, 2012. Published December $17,2012$. 
and, to a lesser extent, of monocytes (3). After a recovery period, a decrease in lymphocyte numbers, which lasts 3 to $6 \mathrm{~h}$, has been reported $(3,4)$. These alterations compromise the body's defense against infection and oncogenic agents, as well as allergic processes and auto-immunity $(1,4)$.

Thus, the intensity, volume, and frequency of exercise play a key role in determining the immune responses to an effort and may increase or reduce the immune function (5). Regular exercise and/or physical training of moderate intensity improve the defense systems, represented by high levels of leukocytes preparing the body to fight against infections (6). On the other hand, intense training causes immune suppression with increased susceptibility to infections (6).

One explanation for the immune suppression, i.e., the fragility of the immune system (reduced number of leukocytes), which makes the body more susceptible to the invasion of pathogens in response to an intense physical exercise load, may be an increased use of body functions with exaggerated ROS production and increased oxidative stress in tissues (7).

It is recognized that free radicals, besides being among the factors that cause damage to the body due to acute physical exercise, also influence the immune system and essential metabolic functions (8). Oxidative stress occurs when the action of free radicals exceeds the activity of antioxidants (9). The production of ROS in response to acute exercise sessions may help the organism to improve its antioxidant capacity chronically. However, if the body does not have the time necessary to recover, this high production of ROS may be harmful, negatively affecting the immune response.

Indirect assessment of oxidative stress involves the measurement of the more stable molecular products formed via the reaction of ROS with certain biomolecules. Some of the common molecular products are the concentrations of oxidation target products, including lipid peroxidation endproducts, like malondialdehyde (MDA) and thiobarbituric acid reactive substances (TBARS) and oxidized proteins (protein carbonyls) (9). Additionally, oxidative stress can be measured by observing alterations in the body's antioxidant defense system. This is typically done by measuring the redox changes in glutathione. Moreover, the activity of certain antioxidant enzymes [superoxide dismutase (SOD) and catalase (CAT)] can be assessed as indicators of the oxidative stress imposed on the tissue. One of the main consequences of oxidative stress is lipid peroxidation and a possible damage to proteins and DNA, thus altering cell function (9). On the other hand, the production of ROS, besides having the potential to increase the antioxidant capacity of the body, can act as a cell signal for protein turnover and synthesis, being beneficial to the organism (8).

Moreover, in situations of poor periodicity of exercise, ROS can induce a condition known as overreaching, which is a disturbance of the metabolic and recuperative systems
$(7,10)$. Overreaching is a desirable state that follows a highintensity exercise bout, promoting an elevated activity of the immune response. It is also characterized by a fast recovery and a positive physiological adaptation phase in response to exercise. Overreaching can be easily reversed in a few days or weeks. This condition of change in performance occurs before a much more serious and harmful situation to the body, i.e., overtraining, which, in addition to specific signs of metabolic fatigue, induces severe neuroendocrine disorders $(7,10)$. A sustained and dramatic impairment of physical performance occurs with overtraining due to excessive exercise sessions (high-intensity or high-volume training) associated with inadequate recovery periods. The decreased activity of the antioxidant defense system only becomes worrisome if after a period of recovery the body does not restore the redox balance.

Today it is clear that acute aerobic and anaerobic exercise can potentially result in increased free-radical production, which may or may not result in acute oxidative stress (11). However, only a few single-study reports have so far compared the effects of anaerobic exercise and aerobic exercise on oxidative stress $(12,13)$ and no studies were found about intermittent intense aerobic exercise or comparing intermittent and resistance exercise protocols in terms of oxidative stress and immunological parameters in middle-aged women. Resistance exercise is characterized by the use of energy above critical power and supplied via the anaerobic metabolism, which results in high accumulation of lactic acid. Long periods of ischemia elicit high xanthine oxidase activation and low $\mathrm{VO}_{2 \mathrm{max}}$ is required when compared to intermittent exercise (14). Intermittent exercise, such as spinning, is characterized by the use of aerobic metabolism with short periods of anaerobic metabolism, in which the energy is produced primarily by the use of oxygen (high $\mathrm{VO}_{2 \max }$ ), without much accumulation of lactic acid. The periods of reperfusion are longer than the periods of ischemia, generating less activation of xanthine oxidase when compared to resistance exercise (14).

It is fairly well accepted that ROS production and the subsequent tissue damage resulting from aerobic exercise are mainly due to an increased flux of electron transport leading to an increased leakage of superoxide radicals, while the generation of ROS during and following anaerobic exercise may be mediated by a variety of other pathways (15). These include xanthine and NADPH oxidase production, ischemia-reperfusion, prostanoid metabolism, phagocytic respiratory bursts, disruption of iron-containing proteins, and excessive calcium accumulation, often resulting from the performance of muscle-damaging isotonic or eccentric biased muscle actions, which commonly produce muscle injury (15).

There is a lack of knowledge about the alterations that occur due to an acute session of resistance exercise as well as intermittent intense aerobic exercise in middle-aged women. This emphasizes the importance of this investiga- 
tion mainly because health professionals are required to have a good understanding of the processes occurring in a woman's body during this period of life as well as in situations where physical abilities are required, as in the case of an exercise session (16). Thus, the present study can provide information for health professionals in order to avoid overtraining by recommending proper exercise.

In order to understand the potential health benefits or harmful effects that may be incurred by intensive exercise, the study of the biochemical variables involved in an exercise session in middle-aged women is extremely important. Thus, the aim of this study was to analyze the effect of an intermittent exercise session and a resistance exercise session on blood cell counts and oxidative stress in middle-aged women.

\section{Material and Methods}

\section{Experimental group}

Thirty-four healthy women aged 45 to 55 years were selected for this study. They had normal blood pressure and were free from diabetes mellitus, obesity, alcoholism, cigarette smoking, and chronic diseases. Moreover, they had not been submitted to any pharmacological therapy during the month before the study. The women were divided into three groups:

Resistance exercise (RE) group. Twelve women engaged in resistance exercises twice a week for at least 2 years at fitness centers in Santa Maria, RS.

Spinning group. Twelve women engaged in spinning activity twice a week for at least 2 years at fitness centers in Santa Maria, RS.

Control group. Ten sedentary women.

The women were informed of the purpose, nature, and possible side effects involved in the study, and gave their informed written consent. The protocol was approved by the Human Ethics Committee of the Centro de Ciências Naturais e Exatas, Universidade Federal de Santa Maria, Brazil (protocol No. 0288.0.243.000-09). Moreover, the ethical issues of the Declaration of Helsinki (1986) from the World Medical Association were considered in this research.

\section{Procedures}

All participants underwent physical assessment before the day of data collection, which included body composition assessment, measurement of heart rate (HR) and blood pressure (BP) at rest, measurement of body mass index (BMI), waist-to-hip ratio (WHR), and one-repetition maximal (1-RM) test to estimate a load of approximately $75 \%$ of maximum strength for the RE group.

Before the experiment, all subjects received a medical certificate proving that they were able to perform physical tests. Experiments began at the same time of day to avoid circadian and circaseptan effects. Data collection was performed on 3 days, 1 day per group.

On the first day, procedures were carried out with the RE group. The session required the completion of a standard circuit of resistance exercises in which three sets of 10 repetitions at 75 to $80 \%$ of $1-\mathrm{RM}$ force were completed at each of the 10 stations: leg press, knee station, hamstring curl, buttocks, hip adduction, hip abduction, bench press, high pull, biceps curl, and triceps curl. In this protocol, exercise sets were usually performed up to muscular failure.

On the second day, procedures were carried out with the spinning group. Subjects performed 50 min of intermittent aerobic exercise on a cycle ergometer used for spinning classes, which was completed at 70 to $85 \%$ of the individual's HR.

In both experiments, subjects remained seated for a 1-h recovery period following the exercises. HR was monitored continuously throughout each session using a Polar ${ }^{\circledR}$ frequency counter (Polar, Brazil) and results are reported as beats per minute. The rating of perceived exertion (RPE) was monitored continuously using a Borg scale (17) and BP was monitored before, immediately after, and $1 \mathrm{~h}$ after the exercise sessions by the auscultatory technique. A blood sample was collected at rest, immediately after, and $1 \mathrm{~h}$ after the exercise sessions.

On the third day, procedures were carried out with the control group. The participants were not submitted to exercise. They remained at rest for $2 \mathrm{~h}$ and the same procedures were performed only once.

\section{Anthropometric measurements}

Body mass was measured with an ARJA $^{\circledR}$ anthropometric scale (Arja, Brazil) with a resolution of $100 \mathrm{~g}$ and body height with a Sanny ${ }^{\circledR}$ stadiometer (Sanny, Brazil). BMI was calculated as weight divided by height squared. WHR was calculated as waist measurement divided by hip measurement. The standard cut-off points recommended by the World Health Organization were used for BMI and WHR (18).

Percent body fat was estimated by the method of skin folds, which are measured with an adipometer CESCORF ${ }^{\circledR}$ (CESCORF, Brazil) with a resolution of $1 \mathrm{~mm}$. Percent body fat was determined using the Jackson et al. (19) equation.

\section{Sample collection}

Venous blood was collected into tubes containing or not an anticoagulant. Serum was obtained by centrifugation at $1800 \mathrm{~g}$ for $10 \mathrm{~min}$ and the solids were discarded. Serum was then used to determine the following: glucose, lipid profile, TBARS, and protein carbonyl. For non-protein sulfhydryl (NPSH), blood was collected using EDTA as anticoagulant. The sample was then centrifuged at $1800 \mathrm{~g}$ for $10 \mathrm{~min}$ and plasma thiols were determined. CAT and SOD activities were determined using whole blood collected into citrated tubes and diluted 1:10 in saline. The samples were kept at 
$-80^{\circ} \mathrm{C}$ until analysis. Total blood with EDTA was used for the hematological determinations, with counts performed immediately afterwards.

\section{Evaluation of glucose and lipid profile}

Glucose, serum total cholesterol, and triglyceride concentrations were measured by standard enzymatic methods using Ortho-Clinical Diagnostics ${ }^{\circledR}$ (Johnson and Johnson, USA) reagents in an automated analyzer (Vitros $950^{\circledR}$ dry chemistry system; Johnson and Johnson). Highdensity lipoprotein (HDL) cholesterol was measured in the plasma supernatant after precipitation of apolipoprotein B-containing lipoproteins with dextran sulfate and magnesium chloride (20).

\section{Hematological determinations}

Quantitative determinations of white blood cells, hemoglobin, hematocrit, platelets, and percentages of lymphocytes, monocytes and granulocytes obtained by venipuncture were performed using a Coulter-STKS analyzer (USA).

\section{Determination of lipid peroxidation}

Lipid peroxidation was estimated by measuring TBARS in serum samples according to the method of Jentzsch et al. (21), modified. Briefly, $0.2 \mathrm{~mL}$ serum was added to the reaction mixture containing $1 \mathrm{~mL} 1 \%$ ortho-phosphoric acid, $0.25 \mathrm{~mL}$ alkaline solution of thiobarbituric acid (final volume $2.0 \mathrm{~mL}$ ) followed by $45 \mathrm{~min}$ heating at $95^{\circ} \mathrm{C}$. After cooling, samples and standards of MDA were read at 532 $\mathrm{nm}$ against the blank of the standard curve. The results are reported as $\mathrm{nmol} \mathrm{MDA} / \mathrm{mL}$ plasma.

\section{Carbonylation of serum protein}

The carbonylation of serum proteins was determined by the method of Levine et al. (22), modified. Proteins were precipitated from $1 \mathrm{~mL}$ serum using $0.5 \mathrm{~mL} 10 \%$ TCA and centrifuged at $1800 \mathrm{~g}$ for $5 \mathrm{~min}$, and the supernatant was discarded. Next, $0.5 \mathrm{~mL} 10 \mathrm{mM}$ 2.4-dinitrophenylhydrazine (DNPH) in $2 \mathrm{M} \mathrm{HCl}$ was added to this precipitate protein and incubated at room temperature for $30 \mathrm{~min}$. During incubation, the samples were mixed vigorously every $15 \mathrm{~min}$. After incubation, $0.5 \mathrm{~mL} 10 \%$ TCA was added to the protein precipitate and centrifuged at $1800 \mathrm{~g}$ for 5 min. The supernatant was discarded, the precipitate was washed twice with $1 \mathrm{~mL}$ ethanol/ethylacetate (1:1) and the supernatant was centrifuged out in order to remove the free DNPH. The precipitate was dissolved in $1.5 \mathrm{~mL}$ protein dissolving solution (2 $\mathrm{g}$ SDS and $50 \mathrm{mg}$ EDTA in $100 \mathrm{~mL} 80 \mathrm{mM}$ phosphate buffer, $\mathrm{pH}$ 8.0) and incubated at $37^{\circ} \mathrm{C}$ for $10 \mathrm{~min}$. The color intensity of the supernatant was measured using a spectrophotometer at $370 \mathrm{~nm}$ against 2 $\mathrm{M} \mathrm{HCl}$. Carbonyl content was calculated using the molar extinction coefficient $\left(21 \times 10^{3} \mathrm{~L} \cdot \mathrm{mol}^{-1} \cdot \mathrm{cm}^{-1}\right)$ and the results are reported as $\mathrm{nmol} / \mathrm{mg}$ protein.

\section{Determination of non-protein thiols}

Non-protein thiols were assayed in plasma by the method of Ellman (23). Aliquots $(0.1 \mathrm{~mL})$ of plasma were added to $0.85 \mathrm{~mL} 0.3 \mathrm{M}$ phosphate buffer, $\mathrm{pH} 7.4$, and the reaction was read at $412 \mathrm{~nm}$ after the addition of $10 \mathrm{mM}$ 5-5'-dithio-bis(2-nitrobenzoic acid) $(0.05 \mathrm{~mL})$. Data are reported as $\mu \mathrm{mol} / \mathrm{mL}$ plasma.

\section{CAT and SOD activities}

CAT activity was determined by the method of Nelson and Kiesow (24), modified. This assay involves the change in absorbance at $240 \mathrm{~nm}$ due to CAT-dependent decomposition of hydrogen peroxide. An aliquot $(0.02 \mathrm{~mL})$ of blood was homogenized in potassium phosphate buffer, $\mathrm{pH}$ 7.0. The spectrophotometric determination was initiated by the addition of $0.07 \mathrm{~mL}$ in an aqueous solution of hydrogen peroxide $(0.3 \mathrm{M})$. The change in absorbance at $240 \mathrm{~nm}$ was measured for $2 \mathrm{~min}$. CAT activity was calculated using the molar extinction coefficient $\left(0.0436 \mathrm{~cm}^{2} / \mu \mathrm{mol}\right)$ and the results are reported as $\mathrm{pmol} / \mathrm{mg}$ protein.

The measurement of SOD activity is based on the inhibition of the radical superoxide reaction with adrenalin as described by McCord and Fridovich (25). In this method, SOD present in the sample competes with the detection system for radical superoxide. One SOD unit is defined as the amount of enzyme that inhibits by $50 \%$ the speed of adrenalin oxidation. The oxidation of adrenalin leads to the formation of the colored product, adrenochrome, which is detected by spectrophotometry. SOD activity is determined by measuring the speed of adrenochrome formation observed at $480 \mathrm{~nm}$ in a reaction medium containing glycine- $\mathrm{NaOH}$ (50 mM, pH 10) and $1 \mathrm{mM}$ adrenalin.

\section{Statistical analysis}

Data were analyzed statistically using the SAS program, version 9.1. A descriptive analysis of the data was first carried out, followed by the application of the Shapiro Wilk normality test, which showed that our data did not follow a normal distribution. Thus, the Wilcoxon test was used for comparison of the three different times (at rest, after exercise and after recuperation) in the same group and the Mann-Whitney test was used for comparison between different groups (sedentary, spinning and RE). Correlations were analyzed by the Pearson test. The level of significance was set at 0.05 in all analyses.

\section{Results}

Table 1 shows the characteristics of the variables age, body mass, stature, BMI, WHR, fat percentage, fat mass, and lean mass for the three groups included in the study. The data show that the groups were homogeneous and all participants had good levels of fat percentage, BMI classified as normal (18), and WHR indicating low risk for the development of heart problems (18). 
Table 1. Characteristics of the participants of the present study.

\begin{tabular}{lccc}
\hline Variables & Control group $(\mathrm{N}=10)$ & RE group $(\mathrm{N}=12)$ & Spinning group $(\mathrm{N}=12)$ \\
\hline Age $($ years $)$ & $47.66 \pm 2.65$ & $47.81 \pm 3.682$ & $48.88 \pm 3.88$ \\
Body mass $(\mathrm{kg})$ & $65.41 \pm 5.41$ & $58.30 \pm 7.36$ & $60.10 \pm 5.08$ \\
Stature $(\mathrm{cm})$ & $1.62 \pm 0.04$ & $1.63 \pm 0.032$ & $1.61 \pm 0.05$ \\
BMI $\left(\mathrm{kg} / \mathrm{m}^{2}\right)$ & $24.56 \pm 1.27$ & $21.65 \pm 2.87$ & $22.74 \pm 1.63$ \\
WHR & $0.75 \pm 0.04$ & $0.72 \pm 0.68$ & $0.72 \pm 0.03$ \\
Body fat $(\%)$ & $24.68 \pm 2.19$ & $21.03 \pm 4.03$ & $22.85 \pm 3.13$ \\
Fat body mass $(\mathrm{kg})$ & $17.95 \pm 3.16$ & $12.70 \pm 3.82$ & $15.52 \pm 5.05$ \\
Lean body mass $(\mathrm{kg})$ & $48.18 \pm 2.42$ & $45.66 \pm 4.11$ & $46.22 \pm 4.27$ \\
\hline
\end{tabular}

Data are reported as means $\pm \mathrm{SD}$. RE = resistance exercise; $\mathrm{BMI}=$ body mass index; $\mathrm{WHR}=$ waist-to-hip ratio. There were no significant differences between groups (Mann-Whitney test).

Table 2. Cardiovascular and biochemical variables at rest, after exercise and $1 \mathrm{~h}$ after recuperation.

\begin{tabular}{|c|c|c|c|c|c|c|c|}
\hline \multirow[t]{2}{*}{ Variables } & \multirow[t]{2}{*}{$\begin{array}{l}\text { Control group } \\
\qquad(\mathrm{N}=10)\end{array}$} & \multicolumn{3}{|c|}{$\begin{array}{l}\text { RE group } \\
(N=12)\end{array}$} & \multicolumn{3}{|c|}{$\begin{array}{l}\text { Spinning group } \\
\qquad(N=12)\end{array}$} \\
\hline & & At rest & After exercise & $\begin{array}{c}\text { After } \\
\text { recuperation }\end{array}$ & At rest & After exercise & $\begin{array}{c}\text { After } \\
\text { recuperation }\end{array}$ \\
\hline HR (bpm) & $86.83 \pm 6.30^{\#}$ & $71.81 \pm 4.46^{\star a}$ & $142.54 \pm 5.58^{b}$ & $70.50 \pm 4.14^{a}$ & $68.11 \pm 7.07^{\star a}$ & $167.66 \pm 17.36^{\mathrm{b}}$ & $62.83 \pm 4.79$ \\
\hline $\mathrm{SBP}(\mathrm{mmHg})$ & $121.66 \pm 7.52$ & $114.54 \pm 6.87$ & $117.27 \pm 13.48$ & $114.40 \pm 6.85$ & $120.66 \pm 8.0$ & $118.33 \pm 12.98$ & $114.00 \pm 8.00$ \\
\hline $\mathrm{DBP}(\mathrm{mmHg})$ & $81.66 \pm 7.52$ & $74.545 \pm 7.22$ & $74.18 \pm 10.21$ & $75.00 \pm 7.07$ & $81.11 \pm 10.54$ & $77.77 \pm 6.66$ & $76.66 \pm 5.16$ \\
\hline RPE (6-20) & $6.00 \pm 0$ & $6.00 \pm 0^{\mathrm{a}}$ & $17.81 \pm 1.25^{b}$ & $6.00 \pm 0^{a}$ & $6.00 \pm 0^{a}$ & $16.66 \pm 1.73^{b}$ & $6.00 \pm 0^{\mathrm{a}}$ \\
\hline Glucose (mg/dL) & $117.50 \pm 11.8^{\#}$ & $102.54 \pm 14.47^{*}$ & $95.90 \pm 7.8$ & $98.00 \pm 7.54$ & $113.11 \pm 14.45^{\# *}$ & $105.33 \pm 14.46$ & $108.00 \pm 5.65$ \\
\hline Cholesterol (mg/dL) & $177.33 \pm 27.1^{\#}$ & $138.00 \pm 18.37^{*}$ & $143.90 \pm 20.06$ & $134.20 \pm 19.06$ & $144.66 \pm 19.03^{*}$ & $153.33 \pm 12.00$ & $145.33 \pm 15.66$ \\
\hline HDL-C (mg/dL) & $47.50 \pm 11.50^{\#}$ & $63.36 \pm 10.99^{*}$ & $66.36 \pm 11.61$ & $61.50 \pm 11.02$ & $59.66 \pm 9.95^{\star}$ & $63.77 \pm 10.90$ & $59.83 \pm 10.49$ \\
\hline Triglycerides (mg/dL) & $310.33 \pm 173.5^{\#}$ & $90.36 \pm 31.18^{*}$ & $101.18 \pm 45.09$ & $99.70 \pm 40.86$ & $127.77 \pm 50.10^{*}$ & $145.22 \pm 46.14$ & $125.00 \pm 49.80$ \\
\hline Monocytes (\%) & $7.30 \pm 1.8$ & $6.52 \pm 1.11 \mathrm{ab}$ & $7.04 \pm 1.97^{a}$ & $5.66 \pm 1.16^{b}$ & $6.74 \pm 1.36^{a b}$ & $7.65 \pm 0.89^{a}$ & $5.20 \pm 1.16^{b}$ \\
\hline
\end{tabular}

Results are reported as means $\pm \mathrm{SD}$. RE = resistance exercise; HR = heart rate; SBP and DBP = systolic and diastolic blood pressures, respectively; RPE = rating of perceived exertion; HDL-C = high-density lipoprotein cholesterol. Different superscript letters indicate statistically significant differences between times of blood collection (rest, after exercise and after recuperation) in the same group $\left(P<0.05\right.$, Wilcoxon test). Different symbols $\left(\#,{ }^{*}\right)$ indicate a statistically significant difference between groups at rest $(P<0.05$, Mann-Whitney test).

Table 2 shows the cardiovascular and biochemical variables at rest, after exercise, and after recuperation of the RE, spinning, and control groups. We observed that there is a statistically significant difference between the RE and spinning groups and the control group regarding HR. At rest and after recuperation, the RE and spinning groups presented a lower HR than the control group $(P<0.05)$. After exercise, the RE and spinning groups had a larger increase of HR compared to the rest situation in the same groups and to the control group $(P<0.05)$.

No significant difference in BP was observed between the RE and spinning groups as a result of the exercises. RPE did not differ between groups when participants were at rest. However, a significant increase $(P<0.05)$ was observed after exercise, when participants felt intense physical effort as determined by a mean value $( \pm S D$ ) of $17.81 \pm 1.25$ on the Borg scale (17) for the RE group and of
$16.66 \pm 1.73$ for the spinning group.

Glucose was significantly higher $(P<0.05)$ in the control group than in the RE and spinning groups at rest. However, no difference in this variable was observed between the exercise groups.

None of the exercises tested induced significant changes in cholesterol, HDL cholesterol, or triglycerides. On the other hand, the RE and spinning groups had significantly better values at rest compared to control, showing lower cholesterol values $(138.00 \pm 18.37 \mathrm{mg} / \mathrm{dL}$ for the RE group, $144.66 \pm 19.03 \mathrm{mg} / \mathrm{dL}$ for the spinning group, and $177.33 \pm$ $27.1 \mathrm{mg} / \mathrm{dL}$ for the control group, $\mathrm{P}<0.05)$ and triglyceride values $(90.36 \pm 31.18 \mathrm{mg} / \mathrm{dL}$ for the RE group, $127.77 \pm$ $50.10 \mathrm{mg} / \mathrm{dL}$ for the spinning group, and $310.33 \pm 173.5$ $\mathrm{mg} / \mathrm{dL}$ for the control group, $\mathrm{P}<0.05)$, but higher $\mathrm{HDL}$ cholesterol values $(63.36 \pm 10.99 \mathrm{mg} / \mathrm{dL}$ for the RE group, $59.66 \pm 9.95 \mathrm{mg} / \mathrm{dL}$ for the spinning group, and $47.50 \pm$ 
$11.50 \mathrm{mg} / \mathrm{dL}$ for the control group, $\mathrm{P}<0.05$ ) at rest.

No differences were found in white blood cells, hemoglobin, hematocrit, or percentages of monocytes or granulocytes between the groups at rest (some data not shown). Lymphocyte percentage (Figure 1) was markedly reduced after 1-h recuperation in the spinning group (from $35.4 \pm$ 2.1 to $30.3 \pm 1.8 \%$ ) and the RE group (from $38.1 \pm 3$ to 27.2 $\pm 3 \%$ ) compared to the time immediately after exercise $(P$ $<0.05$ ). Monocytes (Table 2) were also decreased after $1-\mathrm{h}$ recuperation compared to the time immediately after exercise $(P<0.05)$.

Figures 2 and 3 show oxidative stress biomarkers of the RE and spinning groups at rest, after exercise and after recuperation. In both exercised groups, TBARS (Figure 2A) showed an increase in lipid peroxidation after exercise compared to rest (from $16.5 \pm 2$ to $25 \pm 2 \mathrm{nmol} \mathrm{MDA} / \mathrm{mL}$ serum for the spinning group and from $18.6 \pm 1$ to $28.2 \pm 3 \mathrm{nmol}$ $\mathrm{MDA} / \mathrm{mL}$ serum for the RE group, $\mathrm{P}<0.05)$ and a decrease after recuperation (18.8 \pm 2 for the spinning group and 23.1 $\pm 2 \mathrm{nmol} \mathrm{MDA} / \mathrm{mL}$ serum for the RE group, $\mathrm{P}<0.05)$. When both exercised groups were compared to control at rest, no differences were found in this variable.

Protein oxidation, determined by serum protein carbonyl content (Figure 2B), increased in the RE group (from 0.9 \pm 0.2 to $1.5 \pm 0.2 \mathrm{nmol} / \mathrm{mg}$ protein) and in the spinning group (from $1.0 \pm 0.3$ to $1.6 \pm 0.2 \mathrm{nmol} / \mathrm{mg}$ protein) after exercise $(P<0.05)$, and continued to be increased after recuperation $(1.43 \pm 0.2 \mathrm{nmol} / \mathrm{mg}$ protein for the $R E$ group and $1.4 \pm 0.1 \mathrm{nmol} / \mathrm{mg}$ protein for the spinning group, $\mathrm{P}<$ $0.05)$ compared to the rest situation. No differences were found when compared with the control group.

Non-protein thiols (Figure $3 \mathrm{~A}$ ) were reduced in the RE (from $1.27 \pm 0.2$ to $0.86 \pm 0.2 \mu \mathrm{mol} / \mathrm{mL}$ plasma) and spinning (from $1.16 \pm 0.2$ to $0.82 \pm 0.2 \mu \mathrm{mol} / \mathrm{mL}$ plasma) groups immediately after exercise $(P<0.05)$. An increase was observed after $1 \mathrm{~h}$ of recuperation only in the RE group (1.12 \pm 0.2 $\mu \mathrm{mol} / \mathrm{mL}$ plasma, $\mathrm{P}<0.05)$, approaching baseline levels. There was no difference between groups at rest.

SOD activity (Figure 3B) was significantly decreased in the RE group after exercise $(12.7 \pm 2.4 \mathrm{SOD} / \mathrm{mg}$ protein, $\mathrm{P}$ $<0.05)$ and continued to be decreased after recuperation (12.6 $\pm 2.5 \mathrm{SOD} / \mathrm{mg}$ protein, $\mathrm{P}<0.05)$ when compared to the rest situation $(16.0 \pm 2.1 \mathrm{SOD} / \mathrm{mg}$ protein). The same occurred with CAT activity (Figure $3 \mathrm{C}$ ). There was a decrease in CAT activity after exercise $(5.5 \pm 1.4 \mathrm{pmol} / \mathrm{mg}$ protein, $\mathrm{P}<0.05)$, which remained after recuperation $(6.2$ $\pm 2.2 \mathrm{pmol} / \mathrm{mg}$ protein, $\mathrm{P}<0.05)$ when compared to the rest situation $(11.6 \pm 2.6 \mathrm{pmol} / \mathrm{mg}$ protein). It is interesting to note that women who practiced resistance exercise had higher SOD and CAT activities compared to the control group $(P<0.05)$ of sedentary women.

SOD and CAT activities were significantly decreased in the spinning group after exercise $(10.5 \pm 2.2 \mathrm{SOD} / \mathrm{mg}$ protein for SOD and $7.1 \pm 1.1 \mathrm{pmol} / \mathrm{mg}$ protein for CAT, $\mathrm{P}$ $<0.05)$ and continued to be decreased after recuperation

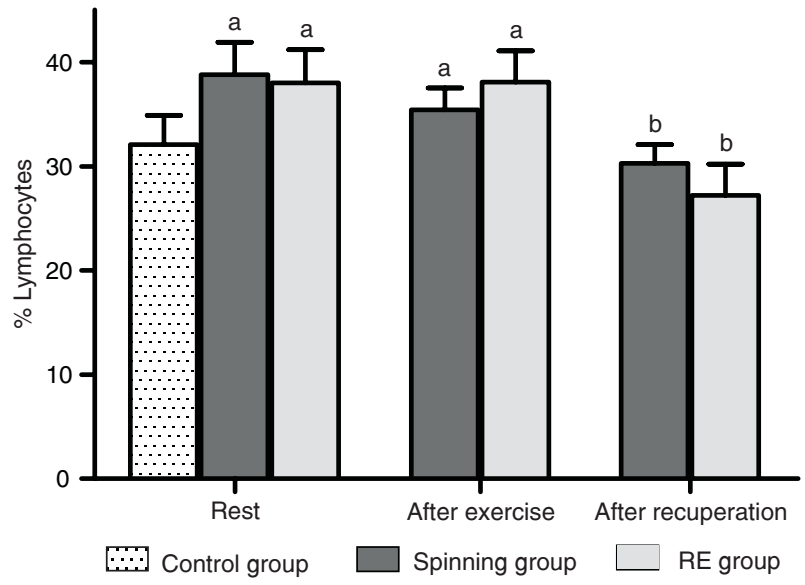

Figure 1. Lymphocyte percentages. Data are reported as means $\pm \mathrm{SD}$. RE = resistance exercise. Different letters indicate a significant difference between times of blood collection (rest, after exercise, and after recuperation) in the same group $(P<0.05$, Wilcoxon test).
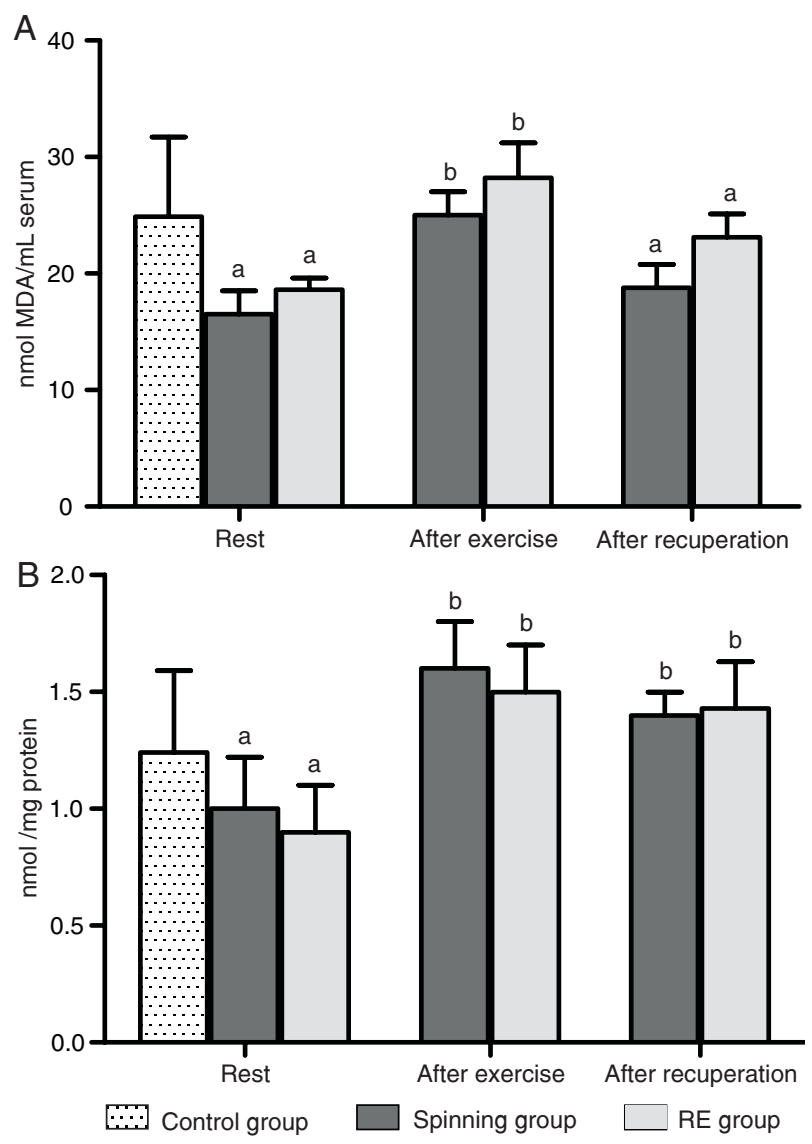

Figure 2. Biomarkers of oxidative damage. $A$, TBARS values and $B$, Protein carbonyl values. Data are reported as means $\pm \mathrm{SD}$. RE $=$ resistance exercise. Different letters indicate a significant difference between times of blood collection (rest, after exercise, and after recuperation) in the same group $(P<0.05$, Wilcoxon test). 

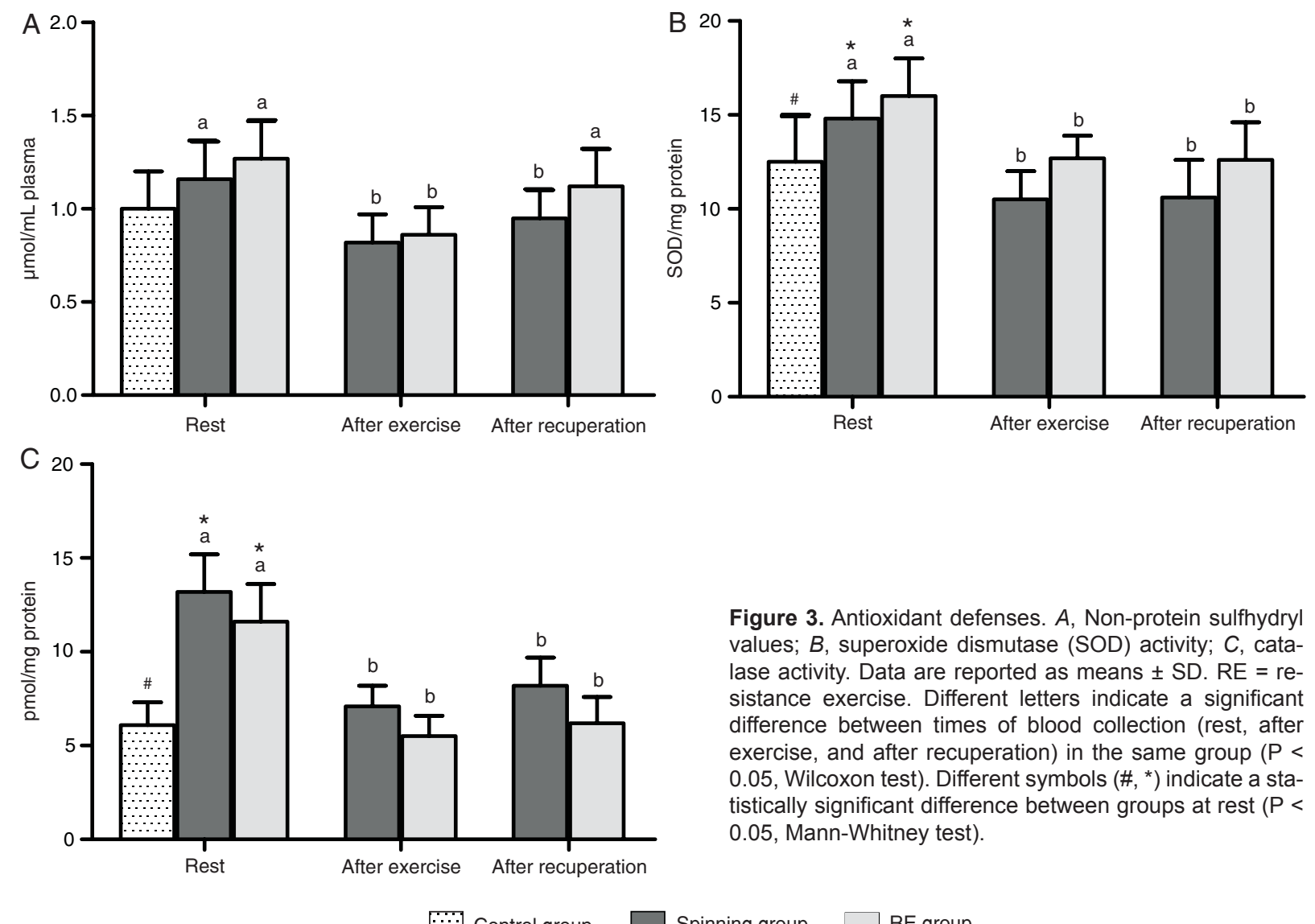

Figure 3. Antioxidant defenses. $A$, Non-protein sulfhydryl values; $B$, superoxide dismutase (SOD) activity; $C$, catalase activity. Data are reported as means $\pm S D$. RE $=$ resistance exercise. Different letters indicate a significant difference between times of blood collection (rest, after exercise, and after recuperation) in the same group $(P<$ 0.05 , Wilcoxon test). Different symbols (\#, *) indicate a statistically significant difference between groups at rest $(\mathrm{P}<$ 0.05, Mann-Whitney test).

Table 3. Correlations between the oxidative stress parameters of the spinning and RE groups after exercise and after recuperation.

\begin{tabular}{lcccccc}
\hline Variables & \multicolumn{2}{c}{ Spinning group $(\mathrm{N}=12)$} & & \multicolumn{2}{c}{$\mathrm{RE}$ group $(\mathrm{N}=12)$} \\
\cline { 2 - 3 } \cline { 5 - 6 } \cline { 5 - 6 } & After exercise & After recuperation & & After exercise & After recuperation \\
\hline TBARS & $-0.912^{*}$ & -0.382 & & $-0.899^{*}$ & -0.768 \\
TBARS and SOD & $-0.942^{*}$ & 0.467 & & $-0.919^{*}$ & 0.433 \\
TBARS and CAT & $-0.948^{*}$ & 0.428 & & $-0.937^{*}$ & 0.376 \\
Carbonyl and NPSH & $-0.922^{*}$ & -0.798 & & $-0.892^{*}$ & 0.533 \\
Carbonyl and SOD & $-0.943^{*}$ & $-0.892^{*}$ & & $-0.956^{*}$ & $-0.925^{*}$ \\
Carbonyl and CAT & $-0.911^{*}$ & $-0.918^{*}$ & & $-0.911^{*}$ & $-0.891^{*}$ \\
\hline
\end{tabular}

Data are reported as $\mathrm{R}$ value. $\mathrm{RE}=$ resistance exercise; TBARS $=$ thiobarbituric acid reactive substances; NPSH = non-protein sulfhydryl groups; SOD = superoxide dismutase; $\mathrm{CAT}$ = catalase. ${ }^{*} \mathrm{P}<0.05$ (Pearson's correlation).

$(10.6 \pm 2 \mathrm{SOD} / \mathrm{mg}$ protein and $8.2 \pm 1.9 \mathrm{pmol} / \mathrm{mg}$ protein, $\mathrm{P}<0.05)$ when compared to the rest situation $(14.8 \pm 2.3$ SOD $/ \mathrm{mg}$ protein for SOD and $13.2 \pm 2.3 \mathrm{pmol} / \mathrm{mg}$ protein for CAT). Moreover, the activity of these two enzymes was higher in women who practiced spinning (at rest) when compared to sedentary women $(P<0.05)$.

Table 3 shows correlations between the oxidative stress parameters of the two exercised groups after exercise and after recuperation. As can be observed, in both groups, immediately after exercise there was a negative correlation 
between lipid and protein oxidation and the antioxidant defenses (NPSH, SOD, and CAT). After 1-h recuperation, a negative correlation between protein carbonyl and enzymatic antioxidant defenses (SOD and CAT) was observed in both groups, showing that this variable did not change even after 1-h recuperation, that is, protein carbonyl remained higher in both groups and SOD and CAT activities remained decreased.

Statistical comparison between the RE and spinning groups (data not shown) showed significant differences only in $\mathrm{HR}$, with the spinning group having higher values after exercise $(P<0.05)$ and lower values after recuperation $(P<$ $0.05)$ compared to the RE group. No significant differences were observed between the excercised groups regarding any other variables analyzed during the experiment.

\section{Discussion}

During the aging process, a natural increase in ROS occurs in women, accompanied by a decrease of the immune response. On the other hand, it is well accepted that regular physical training upregulates antioxidant enzymatic systems and improves the immune system, which may have implications for attenuating the usual increase in aging-related oxidative stress and immune suppression in this population (2). However, until now, no studies have proposed to assess changes in blood cells compared to the production of ROS when analyzing intermittent intense aerobic and resistance exercises. This is the first study that aimed to analyze the effects of intermittent exercise and anaerobic exercise on cardiovascular, immunological and biochemical parameters in middle-aged women.

HR measurement (16) and Borg scale (17) have been used to determine exercise intensity. According to our results, both types of exercise produced significant increases in these parameters, showing that women felt extreme effort when performing high-intensity activities. Indeed, no significant changes in BP were detected. This was probably due to the time elapsed from placing the cuff on the person to completion of the measurement. According to Baum et al. (26), the relaxation interval of $3 \mathrm{~s}$ is sufficient to permit a prompt recovery of BP.

Glucose was analyzed in the postprandial state, explaining the high levels of this variable at rest in all groups. Indeed, the levels of the control group (117.50 $\pm 11.8 \mathrm{mg} /$ $\mathrm{dL}$ ) were significantly higher than those of the other groups (102.54 \pm 14.4 for the RE group and $113.11 \pm 14.3 \mathrm{mg} /$ $\mathrm{dL}$ for the spinning group) perhaps due to the sedentary lifestyle of the subjects. Mondazzi and Arcelli (27) stated that a decline in blood glucose is expected after a bout of physical activity. However, our results showed no significant decrease, probably because these were trained women and their metabolism was already adapted. Cholesterol and triglycerides were lower in the trained women than in the sedentary ones, whereas HDL cholesterol was higher in trained women than in sedentary ones. The better values in women engaged in physical training may be explained by the adaptations to which the body is subjected due to the exercise practice $(28,29)$. Regarding body composition (body mass and BMI), the values of the control group are worse than those of the exercised groups. These results, although not statistically significant, seem to be related to physical training, as extensively reported in the literature (16).

In contrast to data available in the literature $(30,31)$, we did not observe a significant increase in total leukocyte, neutrophil, monocyte, or lymphocyte counts immediately following the two types of exercise. Indeed, the cited studies were conducted on young populations, and perhaps the reason we did not find this increase was due to the fact that the women of our study are in the aging process and their cell defenses may not be responding as they should to such an aggressive stimulus. According to Olsen and Kovacs (32), the low levels of estrogen observed in middleaged women have been shown to attenuate the immune response and to predispose the organism to microbial invasion and infection. Nevertheless, in the present study, estrogen levels were not measured. Thus, further investigation is necessary to find a plausible explanation for the lack of changes in the amount of blood cells immediately after exercise observed here.

However, our results agree with Nieman and NehlsenCannarella (1) who reported that intense exercise induced strong lymphocytopenia $30 \mathrm{~min}$ after exercise. In our study, the last sample was collected $1 \mathrm{~h}$ after exercise, when we found a major decrease in percentages of lymphocytes and monocytes after both exercises. This result shows that intense physical exercise could induce immune suppression, as already well documented by other authors $(1,5,6)$, although not in the population of our study. Our results also agree with Nieman et al. (33) who reported that leg squat exercise induced strong lymphocytopenia, similar in magnitude to the changes reported after endurance exercise. Despite differences in protocols, we can observe that intense exercises show similar responses in terms of the immune system. These responses are highly dependent on the ability of leukocytes to migrate from the blood to peripheral tissues at sites of inflammation (9), in this case, provoked by exercise. Moreover, this immune suppression seems to be linked to the oxidative stress induced by exercise because there is an increased use of the functions of the organism with exaggerated production of ROS and increased oxidative stress in the tissues $(7,8)$.

The most common method used to indicate exerciseinduced oxidative damage has been the assessment of lipid peroxidation through the contents of TBARS (11). Our results showed an increase in TBARS in both exercises, corroborating similar findings in young humans with values typically returning to baseline $1 \mathrm{~h}$ after exercise (34), as also observed in our study. 
Proteins are major targets for ROS (13). Increased protein oxidation, measured by the formation of protein carbonyls (11), has been reported by several investigators $(35,36)$, and remains elevated for several hours after aerobic exercise (36). In our study, protein oxidation also increased after exercise and remained elevated after $1 \mathrm{~h}$ of recuperation, in agreement with the cited studies.

The measurement of NPSH has also been routinely performed for the determination of exercise-induced oxidative stress, and typically a decrease in this biomarker has been reported following a variety of exercise protocols $(11,34,36,37)$; the same result was observed in our study with both protocols. The reduction of NPSH as a result of an acute bout of exercise can be explained by the utilization of this antioxidant defense in an attempt to avoid oxidative stress damage to the body (37). This was reinforced by the negative correlation between TBARS and protein carbonyl and NPSH in both groups immediately after exercise.

Free radical-scavenging enzymes such as SOD and CAT are the first line of cellular defense against oxidative injury (8). Our study showed high levels of these enzymes in trained women (RE and spinning groups) compared to sedentary ones (control group) at rest. This can be explained by the participant training level, which may have improved the endogenous enzymatic antioxidant defenses of trained women $(2,11)$, as observed by the high levels of these two enzymes. It is well established that regular physical training improves antioxidant defenses, making the body adapted to scavenging ROS more easily than in sedentary individuals (2).

As a consequence of the exercise performed by the participants, our study showed a decrease in these antioxidant defenses in both exercise groups, which continued to be reduced after 1 -h recuperation. In this study SOD and CAT decreased immediately after exercise, as also reported by Watson et al. (38) and Steinberg et al. (34). However, these studies showed an increase above basal conditions of these enzymes during the recovery period; results that differ from our study. According to Fisher-Wellman and Bloomer (11), in response to conditions of strenuous physical work, the body antioxidant capacity may be temporarily decreased since its components are used to quench the harmful radicals produced, and this decreased time depends on the intensity of exercise. In our study, the high intensity of both exercises can explain this decrease in enzyme activities. Another explanation for the suppression of SOD and CAT activities is the damage to the proteins that occurred as a consequence of high production of ROS after exercise in both groups, confirmed by the negative correlation with SOD and CAT, which remained even after 1-h recuperation. Furthermore, we observed synergism between the activities of these two enzymes, as described in literature (11).

The same negative correlation was observed between TBARS and antioxidant enzymes immediately after exercise in both the spinning and RE groups. This result indicates that, as the antioxidant enzymes are suppressed probably by the damage to proteins, they cannot exert their effects, and ROS become more available to cause lipid damage. However, after 1 -h recuperation, TBARS returned to baseline levels and enzyme antioxidant defenses did not show the same behavior and no significant correlations were detected. Taking this into account, other mechanisms must be investigated to explain why TBARS levels returned to the levels observed when subjects were at rest and protein carbonyl and enzyme activities did not. One of the explanations for these results may be related to the physical conditioning of the women, which could manage to prevent even more cellular damage, avoiding a prolonged lipid peroxidation.

Bloomer et al. (12) analyzed the effect of acute bouts of anaerobic and aerobic exercises on oxidative stress parameters and did not find differences between the exercise protocols tested, as was also observed in our study. Indeed, they found an indication of oxidative stress, which was not significant, justified by the training of the subjects. We found strong evidence of acute exercise-induced oxidative stress and our study was carried out on trained subjects. This discrepancy can be explained by the age of the individuals studied. A study conducted by Ratiani et al. (39) shows that the decline of the female sex hormone estrogen was correlated with oxidative damage and inflammation. Thus, it is reasonable to assume that the high ROS generation observed after workouts in the present study was also related to the aging process.

Unlike intermittent and aerobic exercises, where increased mitochondrial respiration is thought to be the primary target of increased ROS, it has been suggested that the increased radical production and subsequent oxidative stress observed during and following resistance exercise may be mediated to a large extent by the activities of certain radical-generating enzymes (xanthine and NADPH oxidase), prostanoid metabolism, phagocytic respiratory burst, disruption of iron-containing proteins, as well as altered calcium homeostasis (15). Brief periods of ischemia followed by reperfusion, resulting from intense muscular contraction as well as mechanical stress and/ or muscle damage, are thought to be the mechanisms underlying the increase in ROS triggering the activity of radical- generating enzymes and initiating the migration of inflammatory cells to the affected area (15). Thus, this is the possible explanation for the formation of ROS through anaerobic activity and could be the link between oxidative stress and immune suppression verified in our study.

Thus, our findings indicate that, similar to aerobic exercises, although the mechanisms are not fully understood, anaerobic and intermittent exercises, when performed at high intensity, clearly have the ability to result in acute oxidative stress and immune suppression in middle-aged and trained women. Since $1 \mathrm{~h}$ after exercise we observed a decrease in lymphocytes, a maintained decrease in the enzymatic body defense (SOD and CAT), and a maintained 
increase of protein carbonyl, we could infer that if this kind of exercise is done witt an insufficient recovery period, these metabolic changes, mainly in immunity, may become clinically relevant.

However, based on our data, the consequences of these alterations after a long period of recuperation following an acute exercise session are unknown. We suggest for further studies a larger investigation of whether the alterations induced by both bouts of intermittent and anaerobic exercises performed by the trained women might translate into a maladaptive response or if they could represent a positive adaptation for trained women. This type of investigation could also provide information about how long a sufficient period of recovery should be after different kinds of exercise in this population. In addition, the consequences of an acute bout of intense exercises cannot be extended to untrained individuals who probably do not have the same degree of antioxidant protection as the trained subjects in the present investigation.

Finally, our data comparing trained and sedentary women allow us to conclude that women engaged in intermittent or anaerobic exercise programs seemed to benefit from healthy blood lipid profiles and higher resting antioxidant levels ready to defend against ROS when needed, highlighting the benefits of regular physical activity in this population.

\section{Acknowledgments}

Research supported by CNPq and CAPES.

\section{References}

1. Nieman DC, Nehlsen-Cannarella SL. The immune response to exercise. Semin Hematol 1994; 31: 166-179.

2. Pialoux $\mathrm{V}$, Brown $A D$, Leigh $R$, Friedenreich $C M$, Poulin MJ. Effect of cardiorespiratory fitness on vascular regulation and oxidative stress in postmenopausal women. Hypertension 2009; 54: 1014-1020.

3. Walsh NP, Gleeson M, Shephard RJ, Gleeson M, Woods JA, Bishop NC, et al. Position statement. Part one: Immune function and exercise. Exerc Immunol Rev 2011; 17: 6-63.

4. da Nobrega AC. The subacute effects of exercise: concept, characteristics, and clinical implications. Exerc Sport Sci Rev 2005; 33: 84-87.

5. Ortega E. Neuroendocrine mediators in the modulation of phagocytosis by exercise: physiological implications. Exerc Immunol Rev 2003; 9: 70-93.

6. Simpson RJ, Lowder TW, Spielmann G, Bigley AB, LaVoy EC, Kunz H. Exercise and the aging immune system. Ageing Res Rev 2012; 11: 404-420.

7. Angeli A, Minetto M, Dovio A, Paccotti P. The overtraining syndrome in athletes: a stress-related disorder. J Endocrinol Invest 2004; 27: 603-612.

8. Powers SK, Lennon SL. Analysis of cellular responses to free radicals: focus on exercise and skeletal muscle. Proc Nutr Soc 1999; 58: 1025-1033.

9. Finaud J, Lac G, Filaire E. Oxidative stress: relationship with exercise and training. Sports Med 2006; 36: 327-358.

10. Zoppi CC, Hohl R, Silva FC, Lazarim FL, Neto JM, Stancanneli $M$, et al. Vitamin $C$ and $E$ supplementation effects in professional soccer players under regular training. $J$ Int Soc Sports Nutr 2006; 3: 37-44.

11. Fisher-Wellman K, Bloomer RJ. Acute exercise and oxidative stress: a 30 year history. Dyn Med 2009; 8: 1.

12. Bloomer RJ, Goldfarb AH, Wideman L, McKenzie MJ, Consitt LA. Effects of acute aerobic and anaerobic exercise on blood markers of oxidative stress. J Strength Cond Res 2005; 19: 276-285.

13. Shi M, Wang X, Yamanaka T, Ogita F, Nakatani K, Takeuchi $\mathrm{T}$. Effects of anaerobic exercise and aerobic exercise on biomarkers of oxidative stress. Environ Health Prev Med 2007; 12: 202-208.
14. Gomes EC, Silva AN, de Oliveira MR. Oxidants, antioxidants, and the beneficial roles of exercise-induced production of reactive species. Oxid Med Cell Longev 2012; 2012: 756132.

15. Jackson MJ. Exercise and oxygen radical production by muscle. In: Sen CK, Packer L, Hanninen O (Editors), Handbook of oxidants and antioxidants in exercise. Amsterdam: Elsevier Science; 2000. p 57-68.

16. Garber CE, Blissmer B, Deschenes MR, Franklin BA, Lamonte MJ, Lee IM, et al. American College of Sports Medicine position stand. Quantity and quality of exercise for developing and maintaining cardiorespiratory, musculoskeletal, and neuromotor fitness in apparently healthy adults: guidance for prescribing exercise. Med Sci Sports Exerc 2011; 43: 1334-1359.

17. Borg G. Borg's perceived exertion and pain scales. Champaign: Human Kinetics; 1998.

18. World Health Organization (WHO). Obesity: preventing and managing the global epidemic. Program of Nutrition, Family and Reproductive Health. Geneva: WHO. Technical Report Series; 1998.

19. Jackson AS, Pollock ML, Ward A. Generalized equations for predicting body density of women. Med Sci Sports Exerc 1980; 12: 175-181.

20. Bachorik PS, Albers JJ. Precipitation methods for quantification of lipoproteins. Methods Enzymol 1986; 129: 78-100.

21. Jentzsch AM, Bachmann H, Furst P, Biesalski HK. Improved analysis of malondialdehyde in human body fluids. Free Radic Biol Med 1996; 20: 251-256.

22. Levine RL, Garland D, Oliver CN, Amici A, Climent I, Lenz $A G$, et al. Determination of carbonyl content in oxidatively modified proteins. Methods Enzymol 1990; 186: 464-478.

23. Ellman GL. Tissue sulfhydryl groups. Arch Biochem Biophys 1959; 82: 70-77.

24. Nelson DP, Kiesow LA. Enthalpy of decomposition of hydrogen peroxide by catalase at 25 degrees $\mathrm{C}$ (with molar extinction coefficients of $\mathrm{H}_{2} \mathrm{O}_{2}$ solutions in the UV). Anal Biochem 1972; 49: 474-478.

25. McCord JM, Fridovich I. Superoxide dismutase. An enzymic function for erythrocuprein (hemocuprein). J Biol Chem 
1969; 244: 6049-6055.

26. Baum K, Ruther T, Essfeld D. Reduction of blood pressure response during strength training through intermittent muscle relaxations. Int J Sports Med 2003; 24: 441-445.

27. Mondazzi L, Arcelli E. Glycemic index in sport nutrition. J Am Coll Nutr 2009; 28 (Suppl): 455S-463S.

28. Herzberg GR. Aerobic exercise, lipoproteins, and cardiovascular disease: benefits and possible risks. Can J Appl Physiol 2004; 29: 800-807.

29. Paschalis V, Nikolaidis MG, Giakas G, Theodorou AA, Sakellariou GK, Fatouros IG, et al. Beneficial changes in energy expenditure and lipid profile after eccentric exercise in overweight and lean women. Scand J Med Sci Sports 2010; 20: e103-e111.

30. Natale VM, Brenner IK, Moldoveanu AI, Vasiliou P, Shek P, Shephard RJ. Effects of three different types of exercise on blood leukocyte count during and following exercise. São Paulo Med J 2003; 121: 9-14.

31. Tvede N, Pedersen BK, Hansen FR, Bendix T, Christensen LD, Galbo H, et al. Effect of physical exercise on blood mononuclear cell subpopulations and in vitro proliferative responses. Scand J Immunol 1989; 29: 383-389.

32. Olsen NJ, Kovacs WJ. Gonadal steroids and immunity. Endocr Rev 1996; 17: 369-384.

33. Nieman DC, Henson DA, Sampson CS, Herring JL, Suttles
$\mathrm{J}$, Conley $\mathrm{M}$, et al. The acute immune response to exhaustive resistance exercise. Int J Sports Med 1995; 16: 322-328.

34. Steinberg JG, Delliaux S, Jammes Y. Reliability of different blood indices to explore the oxidative stress in response to maximal cycling and static exercises. Clin Physiol Funct Imaging 2006; 26: 106-112.

35. Bloomer RJ, Davis PG, Consitt LA, Wideman L. Plasma protein carbonyl response to increasing exercise duration in aerobically trained men and women. Int J Sports Med 2007; 28: 21-25.

36. Michailidis $Y$, Jamurtas AZ, Nikolaidis MG, Fatouros IG, Koutedakis Y, Papassotiriou I, et al. Sampling time is crucial for measurement of aerobic exercise-induced oxidative stress. Med Sci Sports Exerc 2007; 39: 1107-1113.

37. Laaksonen DE, Atalay M, Niskanen L, Uusitupa M, Hanninen $\mathrm{O}$, Sen CK. Blood glutathione homeostasis as a determinant of resting and exercise-induced oxidative stress in young men. Redox Rep 1999; 4: 53-59.

38. Watson TA, Callister R, Taylor RD, Sibbritt DW, DonaldWicks LK, Garg ML. Antioxidant restriction and oxidative stress in short-duration exhaustive exercise. Med Sci Sports Exerc 2005; 37: 63-71.

39. Ratiani L, Khorava M, Dgebuadze M, Zhvania N, Sanikidze $\mathrm{T}$. The role of estrogens in pathogenesis of age-related arterial hypertension. Georgian Med News 2012; 71-76. 